\title{
Development, progress and future prospects in cryobiotechnology of Lilium spp.
}

\author{
Jing-Wei Li ${ }^{1,2}$, Xiao-Chen Zhang ${ }^{1}$, Min-Rui Wang ${ }^{1}$, Wen-Lu Bi ${ }^{1,3}$, M. Faisal' ${ }^{4}$, Jaime A. Teixeira da Silva ${ }^{5}$,
} Gayle M. Volk ${ }^{6}$ and Qiao-Chun Wang ${ }^{1 *}$ (D)

\begin{abstract}
Lilium is one of the most popular flower crops worldwide, and some species are also used as vegetables and medicines. The availability of and easy access to diverse Lilium genetic resources are essential for plant genetic improvements. Cryopreservation is currently considered as an ideal means for the long-term preservation of plant germplasm. Over the last two decades, great efforts have been exerted in studies of Lilium cryopreservation and progress has been made in the successful cryopreservation of pollen, seeds and shoot tips in Lilium. Genes that exist in Lilium, including those that regulate flower shape, color and size, and that are resistant to cold stress and diseases caused by fungi and viruses, provide a rich source of valuable genetic resources for breeding programs to create novel cultivars required by the global floriculture and ornamental markets. Successful cryopreservation of Lilium spp. is a way to preserve these valuable genes. The present study provides updated and comprehensive information about the development of techniques that have advanced Lilium cryopreservation. Further ideas are proposed to better direct future studies on Lilium cryobiotechnology.
\end{abstract}

Keywords: Cryopreservation, Genetic stability, Lily, Pollen, Seeds, Shoot tips

\section{Highlights}

- Availability of diverse genetic resources is essential for Lilium genetic improvements;

- Cryopreservation is an ideal means for the long-term preservation of plant germplasm;

- This review provides recent advances in the said field;

- Future prospects are proposed to direct further studies.

\section{Background}

Lilium, a perennial bulb plant, includes approximately 100 species [1]. About 55 species and 32 varieties of Lilium are native to China [2], 21 Lilium species to North

\footnotetext{
*Correspondence: qiaochunwang@nwsuaf.edu.cn

${ }^{1}$ State Key Laboratory of Crop Stress Biology in Arid Region, College of Horticulture, Northwest A\&F University, Yangling 712100, Shaanxi, People's Republic of China

Full list of author information is available at the end of the article
}

America, and 10 Lilium species to European and Caucasus [1].

Lilium is globally grown as one of the most important cut and pot flower and garden crops, mainly due to large, fragrant, multi-colored flowers with a long shelf-life [3, 4]. Lilium species and hybrids are also used as garden plants [3]. The bulbs of some Lilium species including $L$. davidii var. unicolor, $L$. brownii var. viridulum and $L$. lancifolium are widely consumed as vegetables [5] due to their high levels of protein, amino acids, minerals and dietary fiber $[6,7]$. Other Lilium species such as L. regale, L. concolor, L. pumilum, $L$. davidii var. unicolor and $L$. lancifolium are traditional Chinese medicines [8], and they contain biochemical compounds such as alkaloids, polysaccharides, saponin and colchicine that have antioxidant activities $[6,9]$. Lilies have been grown as vegetables and medicine for at least 2000 years in China [10].

A wide diversity of Lilium genetic resources has provided valuable genes for breeding of novel cultivars. There are more than 300 new registrations of Lilium cultivars each year and approximately 9500 cultivars in total 
globally [11]. There is a demand for new, novel lily cultivars from the production industry $[4,12,13]$.

The availability of and easy access to diverse plant genetic resources are essential to provide the valuable genes necessary to develop novel cultivars. Extensive explorations and collections, heavy grazing, forest planting and urban expansions have threatened wild Lilium species [14, 15]. Global climate warming, which has increased the mean temperature of the Earth's surface by approximately $0.8{ }^{\circ} \mathrm{C}$ from the early 1900 s to 2011 [16], has further worsened the situation $[15,17]$. L. tsingtauense, L. polyphyllum, L. pomponium and L. maculatum var. bukosanense are listed as endangered species in China [14], Italy [18], India [15] and Japan [19] respectively. As a result, it is necessary to preserve and protect Lilium genetic resources.

Cryopreservation is a method whereby plant genetic resources can be conserved in liquid nitrogen (LN, $-196{ }^{\circ} \mathrm{C}$ ) or liquid nitrogen vapor (LNV, approx. - 165 to $-190^{\circ} \mathrm{C}$ ) [20-22]. Once stored in liquid nitrogen conditions, cellular divisions of the samples cease, and theoretically, plant materials can be maintained for extended lengths of time [20-23]. Once placed into long-term storage, less space and fewer resources are required to maintain secure collections, compared to field or in vitro collections [20-22]. Cryopreservation eliminates the risk of losing collections as a result of pathogen attacks and unexpected environmental conditions in field collections and reduces the risk of losing cultures by contamination and of genetic variations by repeated subcultures in in vitro collections [20-22].

This review provides updated and comprehensive information on the developments and advances in Lilium cryopreservation. In additional to preserving genetic resources, successful cryopreservation provides a method to conserve valuable genes in Lilium spp. that regulate flower shape, color and size, and that are resistant to cold stress and diseases caused by fungi and viruses. Prospects are proposed to direct further studies on Lilium cryobiotechnology.

\section{Cryopreservation}

Bouman and De Klerk [24] were the first to cryopreserve shoot tips of $L$. speciosum with about $8 \%$ survival. Since then, various cryopreservation methods have been described for Lilium pollen [25], seeds [26-29] and shoot tips [4]. The major cryoprotocols available for Lilium include dehydration $[26,28,29]$, encapsulation-dehydration [29, 30], encapsulation-vitrification [30], vitrification [30-33], and droplet-vitrification [34-38].

Major steps of Lilium cryopreservation for shoot tips, pollen and seeds are provided in Fig. 1.

\section{Shoot tips}

A shoot tip refers to an apical dome and a few leaf primordia that are composed of undifferentiated cells capable of continuous cellular division and giving rise to a shoot [39]. For vegetatively propagated plants for which specific allelic combinations must be preserved, shoot tips are preferred over cell suspensions, seeds and embryogenic tissues for preservation of plant germplasm, because specific genotypes are conserved [20,21]. Lilies are vegetatively propagated in the floriculture industry because specific cultivars must be maintained and therefore, shoot tips are often the preservation target for cryopreserving Lilium germplasm. A list of successful cryopreservation of Lilium shoot tips is presented in Table 1.

\section{Droplet-vitrification}

Vitrification refers to a physical process by which highly concentrated and viscous cryoprotectant mixtures form metastable glasses after rapidly cooling to $\mathrm{LN}$, without the formation of ice crystals between and inside plant cells [40]. Vitrification cryopreservation is among the most often used methods for cryopreserving plant germplasm [21, 22, 41]. Droplet-vitrification combines the advantages of droplet freezing with vitrification, thus allowing samples to obtain rapid cooling and warming rates, increasing the survival of cryopreserved samples $[41,42]$. Droplet-vitrification is considered to be a robust means for the cryopreservation of Lilium shoot tips [32, 34-36, 38, 43].

Chen et al. [36] described a droplet-vitrification for Lilium shoot tips. In their study, 2-months old in vitro lily stock shoots were cold-hardened at $4{ }^{\circ} \mathrm{C}$ for 1 week under a 16-h photoperiod of $35 \mu \mathrm{mol} \mathrm{m}{ }^{-2} \mathrm{~s}^{-1}$ light intensity. Shoot tips excised from the cold-hardened shoots were precultured in liquid Murashige and Skoog [44] medium (MS) supplemented with $0.3 \mathrm{M}$ sucrose for 2 days. Precultured shoot tips were loaded with a loading solution composed of MS supplemented with $2.0 \mathrm{M}$ glycerol and $0.4 \mathrm{M}$ sucrose for $20-40 \mathrm{~min}$ at $22{ }^{\circ} \mathrm{C}$, and exposed to plant vitrification solution 2 (PVS2) [45] for 90-120 min at $0{ }^{\circ} \mathrm{C}$. PVS2 contains $30 \%(\mathrm{w} / \mathrm{v})$ glycerol, $15 \%(\mathrm{w} / \mathrm{v})$ ethylene glycol, 15\% (w/v) dimethylsulfoxide (DMSO) and $0.4 \mathrm{M}$ sucrose in MS (pH 5.8) [45]. Dehydrated shoot tips were transferred to $1.5-\mu \mathrm{L}$ PVS2 droplets placed on sterile aluminum foil strips $(5 \times 30 \mathrm{~mm})$, each strip carrying 5-6 shoot tips. The aluminum foil strips were folded to enclose the shoot tips and directly immersed into LN. For thawing, frozen aluminum foil strips were removed from $\mathrm{LN}$ and immediately placed in $1.2 \mathrm{M}$ sucrose at room temperature for $15 \mathrm{~min}$, followed by post-culture on a recovery medium for shoot regrowth. Recovery medium 


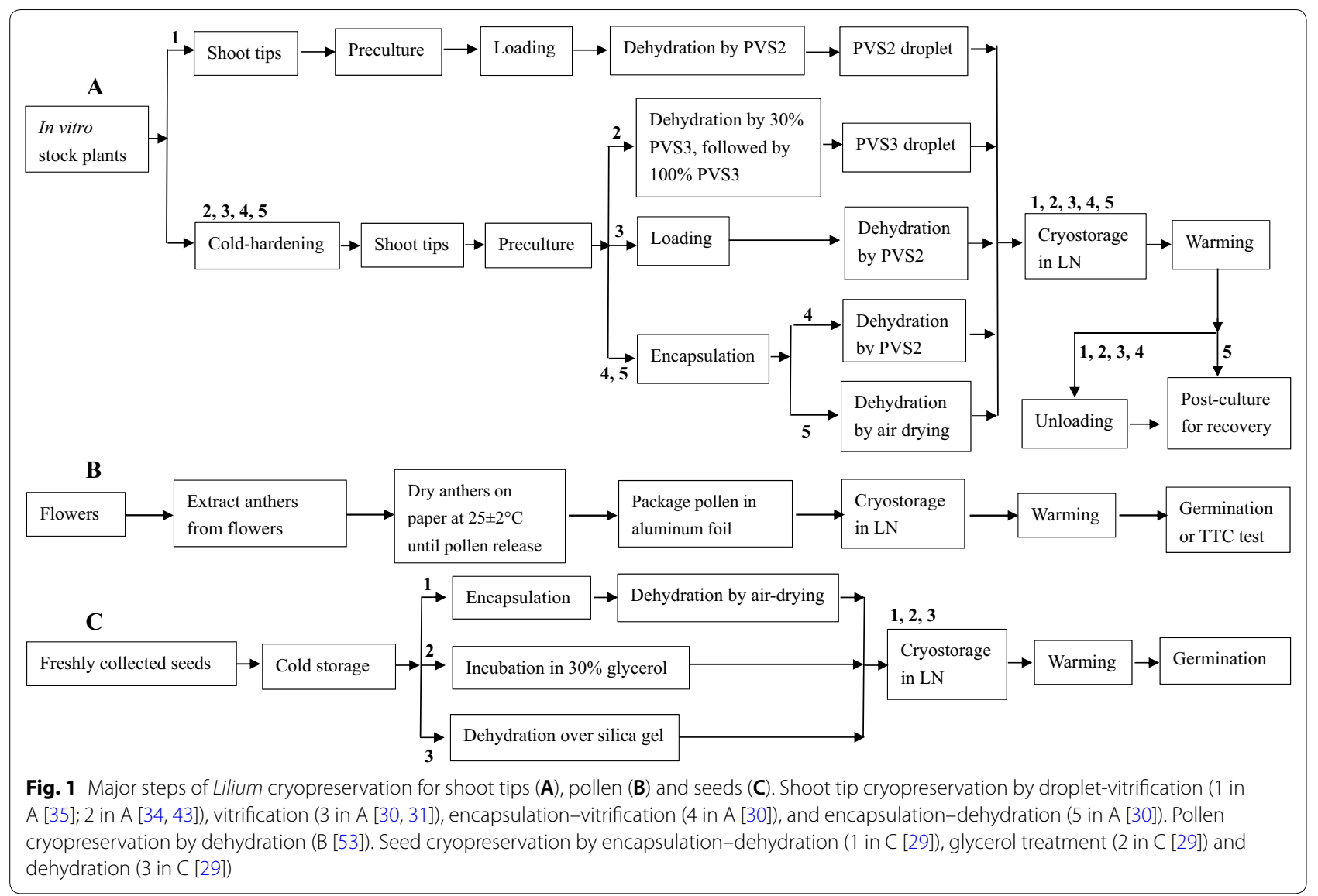

consisted of MS supplemented with $0.5 \mathrm{mg} \mathrm{L}^{-1}$ 6-benzylaminopurine (BA), $0.1 \mathrm{mg} \mathrm{L}^{-1} \alpha$-naphthaleneacetic acid (NAA), $0.3 \mathrm{mg} \mathrm{L}^{-1}$ gibberellic acid $\left(\mathrm{GA}_{3}\right), 30 \mathrm{~g} \mathrm{~L}^{-1}$ sucrose and $7 \mathrm{~g} \mathrm{~L}^{-1}$ agar ( $\left.\mathrm{pH}, 5.7\right)$. The cultures were maintained in the dark for 2 weeks at $20{ }^{\circ} \mathrm{C}$, and then cultured in a 16-h photoperiod of $35 \mu \mathrm{mol} \mathrm{m}^{-2} \mathrm{~s}^{-1}$ light intensity at $20{ }^{\circ} \mathrm{C}$. Survival and shoot regrowth levels obtained by this droplet-vitrification cryoprotocol were $65 \%$ and $62 \%$ for Oriental hybrid 'Siberia', $84 \%$ and $68 \%$ for L. lancifolium and 43 and $35 \%$ for L. $\times$ longiflorum, respectively.

Yi et al. [34, 43] described a droplet-vitrification method for shoot tip cryopreservation of four Oriental hybrids and L. callosum. In their study, 2-week old in vitro stock cultures were cold-hardened for 7 days at $4{ }^{\circ} \mathrm{C}$ in a 16 -h photoperiod of $35 \mu \mathrm{mol} \mathrm{m}{ }^{-2} \mathrm{~s}^{-1}$ light intensity. Shoot tips were then excised from the coldhardened in vitro stock cultures and precultured with $0.3 \mathrm{M}$ sucrose overnight, followed by preculture with $0.7 \mathrm{M}$ sucrose overnight under the same light conditions, as described for cold-hardening. Precultured shoot tips were exposed to $35 \%$ PVS3 [46] at $23^{\circ} \mathrm{C}$ for $40-60 \mathrm{~min}$, followed by exposure to full-strength PVS3 for $240 \mathrm{~min}$, prior to direct immersion in LN. Exposure of shoot tips to $35 \%$ PVS3 produced the highest shoot regrowth in cryopreserved shoot tips: $87.5 \%$ for 'Carmina', $64 \%$ for 'Crystal Light', 53\% for 'Santander' and 68\% for 'Marrero' (61\%), and 78\% for L. callosum [34]. PVS3 contains 50\% $(\mathrm{v} / \mathrm{v})$ glycerol and $50 \%(\mathrm{w} / \mathrm{v})$ sucrose in MS [46]. PVS3 has been found to be less toxic to the cells than PVS2 and appeared to better protect plant tissues against osmotic stress, thus resulting in better survival of shoot tips after cryopreservation [47]. Droplet-vitrification has been applied to cryopreservation of 160 Lilium accessions at the National Academy of Agricultural Sciences in South Korea, including 20 species, one Asiatic hybrid and one Oriental hybrid [43]. The highest and lowest levels of shoot regrowth in cryopreserved shoot tips were $86 \%$ for L. hansonii and $38 \%$ for $L$. henryi, averaging at $56 \%$ for the total Lilium germplasm tested [43].

Cold-hardening $\left(0-5{ }^{\circ} \mathrm{C}\right.$ for $5-7$ days $)$ of in vitro stock shoots was necessary in many of the studies for successful cryopreservation of Lilium shoot tips [24, 30-32, 34, $36,38,43,48]$. Cold hardening requires a temperaturecontrolled growth chamber and is also time consuming. Yin et al. [35] described a droplet-vitrification cryopreservation for lily shoot tips in which cold-hardening of in vitro stock shoots was eliminated. In their study, 


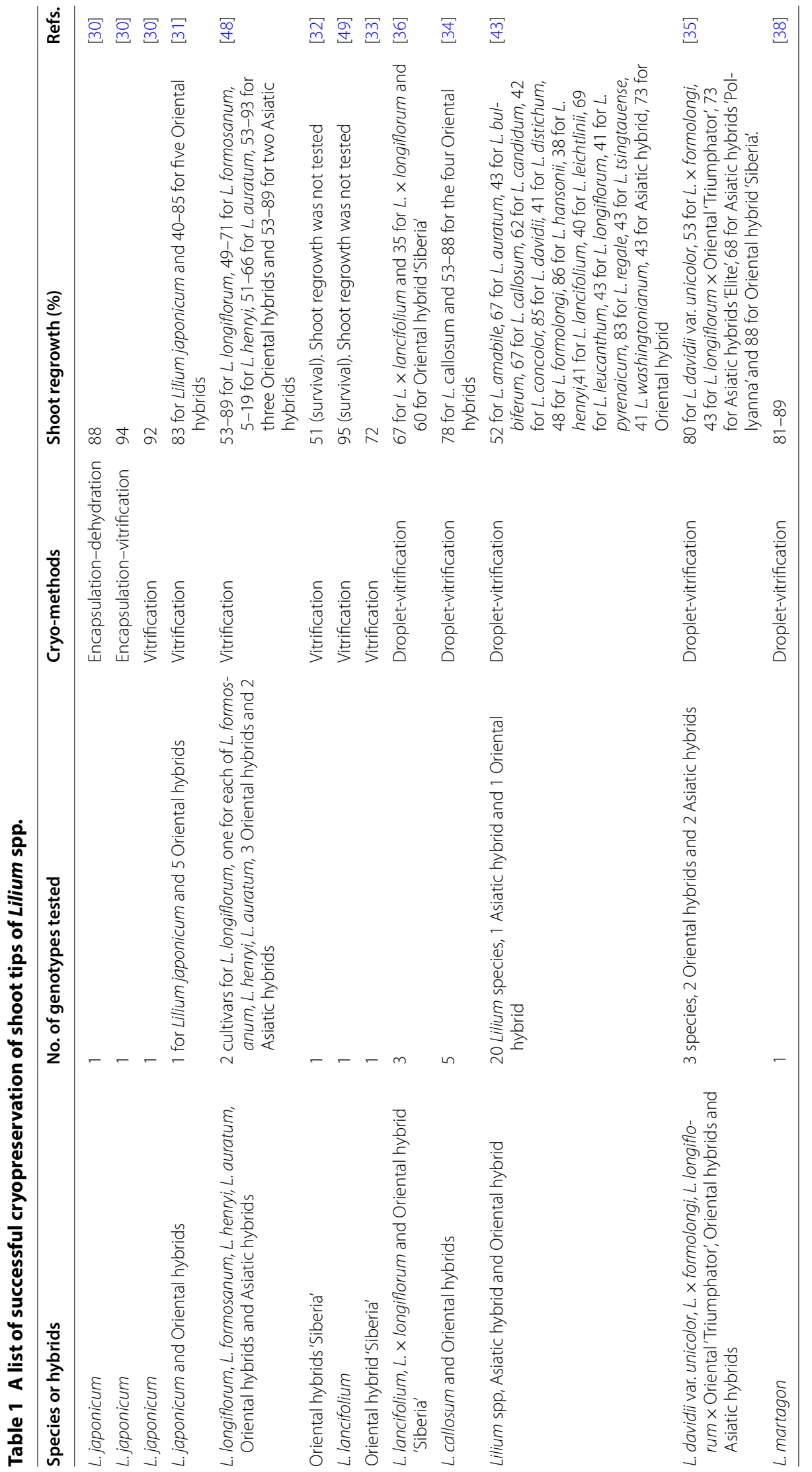


adventitious buds were induced from leaf segments cultured on MS medium supplemented with $1 \mathrm{mg} \mathrm{L}^{-1} \mathrm{NAA}$ and $0.5 \mathrm{mg} \mathrm{L}^{-1}$ thidiazuron (TDZ) in a $16-\mathrm{h}$ photoperiod with a light intensity of $45 \mu \mathrm{mol} \mathrm{m} \mathrm{m}^{-2} \mathrm{~s}^{-1}$. Shoot tips (Fig. 2f) excised from 4-week-old adventitious shoots (Fig. 2e) were cultured on a basal medium (BM) composed of MS containing $30 \mathrm{~g} \mathrm{~L}^{-1}$ sucrose $(\mathrm{pH}, 5.7)$ for 1 day. Shoot tips were precultured on solid MS medium containing $0.5 \mathrm{M}$ sucrose for 1 day and then loaded with a loading solution containing $0.4 \mathrm{M}$ sucrose and $2 \mathrm{M}$ glycerol for $20 \mathrm{~min}$, followed by exposure to PVS2 for $4 \mathrm{~h}$ at $0{ }^{\circ} \mathrm{C}$. Dehydrated shoot tips were transferred onto 2.5- $\mu \mathrm{L}$ PVS2 droplets on aluminum foil strips (Fig. $2 \mathrm{~g}$ ), prior to a direct immersion into LN for cryostorage. Frozen shoot tips were warmed in MS medium containing $1.2 \mathrm{M}$ sucrose for $20 \mathrm{~min}$ at room temperature, followed by post-thaw culture for shoot regrowth on MS medium supplemented with $1 \mathrm{mg} \mathrm{L}^{-1} \mathrm{NAA}$ and $0.2 \mathrm{mg} \mathrm{L}^{-1} \mathrm{TDZ}$ (pH, 5.8). Cultures were placed at $23 \pm 2{ }^{\circ} \mathrm{C}$ in the dark for
3 days and then transferred to the light to assess survival and shoot regrowth. Shoot regrowth levels ranged from $43 \%$ for Oriental hybrid 'Triumphator' to $88 \%$ for Oriental hybrid 'Siberia', with a mean shoot regrowth level of $67 \%$ across the six diverse Lilium genotypes tested.

\section{Vitrification}

Vitrification cryopreservation is among the most often used methods for cryopreserving plant germplasm [21, $22,41]$.

Matsumoto et al. [31] described a method to cryopreserve $L$. japonicum shoot tips using vitrification techniques. In their study, single scale segments $(5 \mathrm{~mm} \times 5 \mathrm{~mm})$ excised from in vitro stock shoots were cultured on a BM composed of MS containing 3\% sucrose to induce adventitious buds. After 40 days of culture, scale segments with adventitious buds were coldhardened at $0{ }^{\circ} \mathrm{C}$ for 28 days in a 12 -h photoperiod of $60 \mu \mathrm{mol} \mathrm{m} \mathrm{m}^{-2} \mathrm{~s}^{-1}$ light intensity. Shoot tips excised from

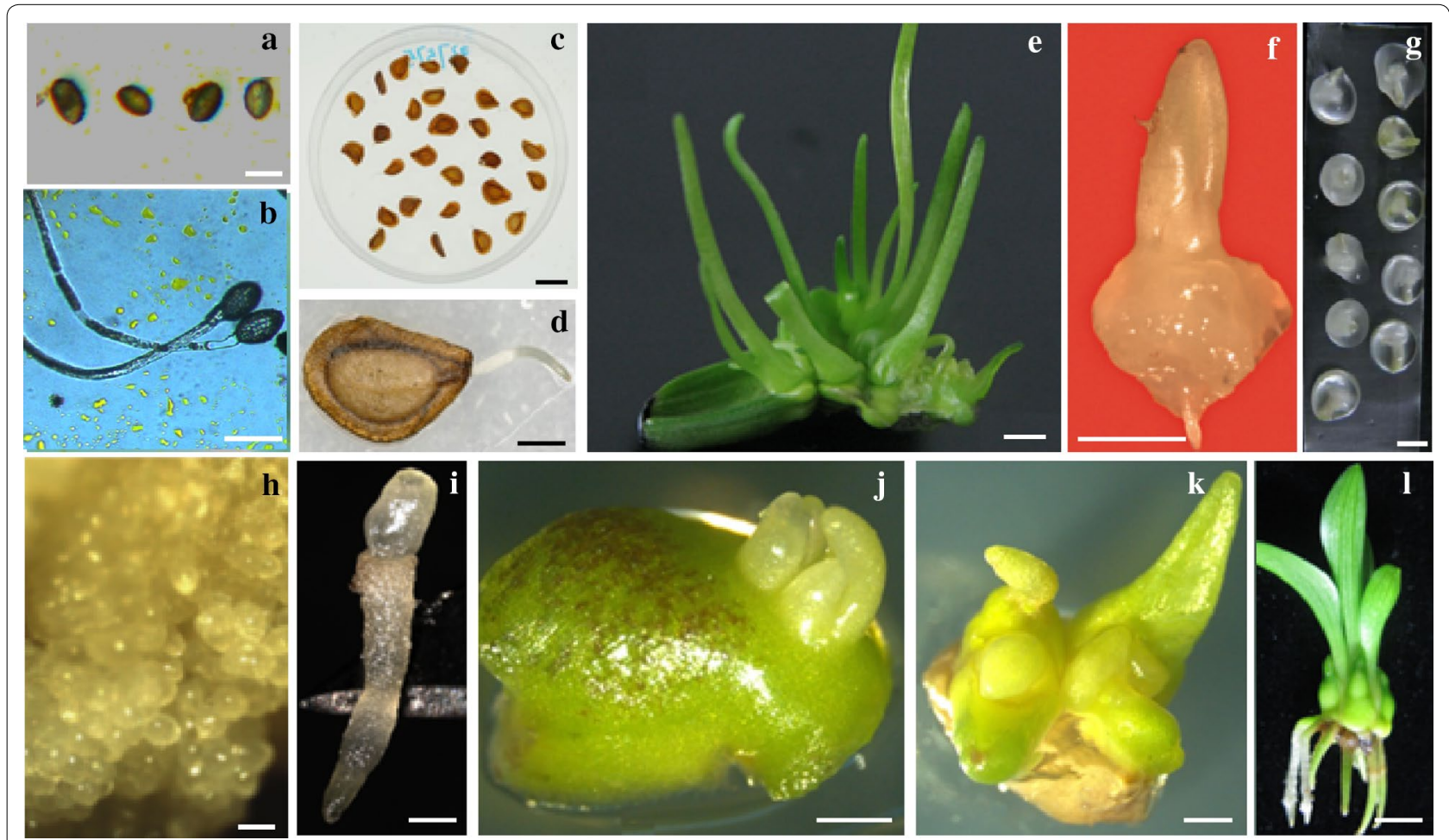

Fig. 2 Cryopreservation of Lilium pollen $(\mathbf{a}, \mathbf{b})$, seeds $(\mathbf{c}, \mathbf{d})$ and shoot tips $(\mathbf{e}-\mathbf{I})$. Oriental hybrid 'Siberia' pollen released from anthers and used for cryopreservation (a) and germinating pollen (b) after cryoexposure (courtesy of Prof. Yan Liu for providing the photos). Surface-disinfected seeds of Lilium brownie used for cryopreservation (c) and germinating seeds (d) after dehydration cryopreservation (courtesy of Dr. Liang Lin for providing the photos). Four-weeks old adventitious buds regenerated from leaf segments of Oriental hybrid 'Siberia' (e). A shoot tip excised from the 4-weeks old adventitious buds in $\mathbf{d}$ (f). PVS2 droplets, each containing one shoot tip, on an aluminum foil strip (g). Somatic embryo-like structures regenerated from cryopreserved shoot tips of Oriental hybrid 'Siberia' after 4 weeks of post-thaw culture (h). A germinating somatic embryo developed from $\mathbf{h}$ after 4 weeks of culture on germinating medium (i). A small leaf square-bearing two adventitious buds of Oriental hybrid 'Siberia' after 4 weeks of induction (j). Shoot regrowth of cryopreserved small leaf square-bearing adventitious buds after 4 weeks of post-thaw culture (k). A plantlet regenerated from cryopreserved shoot tips of Oriental hybrid 'Siberia' after 4 weeks of culture on rooting medium (I). Bars in a and $\mathbf{b}=20 \mu \mathrm{m}$; in $\mathbf{c}$ and $\mathbf{d}=2 \mathrm{~mm}$; in $\mathbf{e}-\mathbf{I}=1 \mathrm{~mm}$ 
the cold-hardened adventitious buds were precultured on the basal medium composed of MS supplemented with $0.3 \mathrm{M}$ sucrose at $25^{\circ} \mathrm{C}$ for 1 day in the light. Precultured shoot tips were placed into $1.8-\mathrm{mL}$ cryotubes and treated with a loading solution composed of $2 \mathrm{M}$ glycerol and $0.4 \mathrm{M}$ sucrose at $25^{\circ} \mathrm{C}$ for $20 \mathrm{~min}$. Loaded shoot tips were then exposed to PVS2 at $0{ }^{\circ} \mathrm{C}$ for $100-110 \mathrm{~min}$ or at $25^{\circ} \mathrm{C}$ for $20 \mathrm{~min}$, prior to direct immersion in LN for cryostorage. For warming, frozen cryotubes containing shoot tips were placed in a water bath at $40^{\circ} \mathrm{C}$ for $2 \mathrm{~min}$. PVS2 was drained from the cryotubes and replaced with $1.8 \mathrm{~mL}$ of 1.2 $\mathrm{M}$ sucrose solution for unloading at $25^{\circ} \mathrm{C}$ for $20 \mathrm{~min}$. Cryopreserved shoot tips were transferred onto sterile filter paper discs placed on the BM in a Petri dish, and placed in the light condition. After 1 day, the shoot tips were transferred onto fresh filter paper discs placed on the same medium and post-cultured in the same light condition for shoot regrowth. This vitrification protocol resulted in $40-85 \%$ of shoot regrowth in cryopreserved shoot tips of the five Oriental hybrids tested, and 83\% in cryopreserved shoot tips of L. japonicum [31]. Vitrification was also successfully applied to shoot tip cryopreservation of four Lilium species [48], Oriental hybrids [32, 48], Asiatic hybrids [48], and L. lancifolium [49].

\section{Encapsulation-vitrification and encapsulation-dehydration}

Encapsulation-vitrification and encapsulation-dehydration are among the most popular cryoprocedures used for plant cryopreservation [21, 22, 41]. These two cryoprocedures both employ an encapsulation step whereby samples are encapsulated with $2.0-3.0 \%(\mathrm{w} / \mathrm{v})$ calcium alginate into beads $(3.0-4.0 \mathrm{~mm}$ in diameter). Beads are dehydrated by exposure to PVS2 in encapsulation-vitrification and by air-drying in encapsulation-dehydration.

Matsumoto and Sakai [30] reported encapsulation-vitrification and encapsulation-dehydration methods for cryopreserving L. japonicum shoot tips. In their study, in vitro stock shoots were cold-hardened and shoot tips were prepared, as described by [31], and then encapsulated with $2 \% \mathrm{Na}$-alginate solution in $0.1 \mathrm{M} \mathrm{CaCl}_{2}$ supplemented with $2 \mathrm{M}$ glycerol and $0.4 \mathrm{M}$ sucrose, to form beads ( $3 \mathrm{~mm}$ in diameter). For the encapsulation-vitrification method, the beads were exposed to PVS2 at $0{ }^{\circ} \mathrm{C}$ for $100 \mathrm{~min}$, and then transferred into $2.0-\mathrm{mL}$ cryotubes, each containing 10 beads and $0.7 \mathrm{~mL}$ PVS2, prior to direct immersion into LN for cryostorage. For regrowth assessment, frozen cryotubes containing shoot tips were warmed in a water bath at $40{ }^{\circ} \mathrm{C}$ for 2 min. PVS2 was drained from the cryotubes and replaced with $1.8 \mathrm{~mL}$ $1.2 \mathrm{M}$ sucrose solution for unloading for $30 \mathrm{~min}$ at $25^{\circ} \mathrm{C}$. For the encapsulation-dehydration method, the beads were dehydrated over sterile filter paper placed in a desiccator containing $50 \mathrm{~g}$ of dried silica gel, which was sealed with Parafilm ${ }^{\circledR}$, at $25{ }^{\circ} \mathrm{C}$ for $4 \mathrm{~h}$, to reduce water content of the beads to about $26 \%$. Dehydrated beads were transferred into $1.8-\mathrm{mL}$ cryotubes and directly immerged in LN for cryostorage. Cryopreserved shoot tips were thawed as described in both encapsulation-vitrification, but without the unloading step using $1.2 \mathrm{M}$ sucrose, as described above. In both the encapsulation-vitrification and encapsulation-dehydration methods, cryopreserved shoot tips were post-cultured for shoot regrowth, as described in vitrification by Matsumoto et al. [31]. This encapsulation-dehydration cryopreservation resulted in $88 \%$ shoot regrowth of L. japonicum.

\section{Pollen}

In Lilium, hybrids are relatively easily obtained by crossing between species of the same section [50]. Longiflorum hybrids, Asiatic hybrids and Oriental hybrids are among the most valuable hybrids widely grown in the world $[3,50]$. Lilium pollen viability differs between cultivars, genus and species, and usually lasts for several days [51]. Efficient preservation of pollen has potential for conserving plant genetic resources and for use in cross breeding [52].

Several laboratories in China have studied the cryopreservation of Lilium pollen [53-55]. Shi et al. [53] reported the cryopreservation of Oriental hybrids 'Sorbonne' and 'Siberia' pollen. Freshly harvested pollen was transferred into $1.5-\mathrm{mL}$ cryotubes. The cryotubes were then placed in a $4 \mathrm{~L}$ desiccator filled with $1.0 \mathrm{~kg}$ silica gels for dehydration at $4{ }^{\circ} \mathrm{C}$ for $2 \mathrm{~h}$, to reduce the water content of pollens to about 7.3-7.7\% (fresh weight basis). Dehydrated pollen was placed at $-20{ }^{\circ} \mathrm{C}$ for $20 \mathrm{~min}$, and then immerged in LN for cryostorage. Cryotubes containing cryopreserved pollen were warmed in a water bath set at $40{ }^{\circ} \mathrm{C}$ for $2 \mathrm{~min}$ and then in vitro germinated at $25^{\circ} \mathrm{C}$ on a germination medium composed of $300 \mathrm{mg} \mathrm{L}^{-1} \mathrm{Ca}\left(\mathrm{NO}_{3}\right)_{2}+200 \mathrm{mg} \mathrm{L}^{-1} \mathrm{MgSO}_{4}+200 \mathrm{mg} \mathrm{L}^{-1}$ $\mathrm{KNO}_{3}+200 \mathrm{mg} \mathrm{L}^{-1} \mathrm{H}_{3} \mathrm{BO}_{4}+20 \mathrm{~g} \mathrm{~L}^{-1}$ sucrose (pH 6.5) in the dark. Pollen germination levels were recorded after $12 \mathrm{~h}$ of culture. Results showed germination levels remained stable and high in pollen cryopreserved for different durations: $60 \%$ and 59\% after 60 days, and $51 \%$ and $48 \%$ after 420 days, for 'Sorbonne' and 'Siberia', respectively.

The pollen of $L$. concolor var. pulchelium was successfully stored at $-80{ }^{\circ} \mathrm{C}$ [55]. Freshly harvested pollens were transferred onto paper tissue placed in a desiccator filled with silica gels for dehydration at room temperature for $8-12 \mathrm{~h}$, to reduce the water content of pollen to $18-22 \%$. Dehydrated pollen was stored directly in a refrigerator at $-80{ }^{\circ} \mathrm{C}$ or pre-frozen in $\mathrm{LN}$ and then transferred to a refrigerator at $-80{ }^{\circ} \mathrm{C}$ for storage. Stored pollen was warmed at $35{ }^{\circ} \mathrm{C}$ for $10 \mathrm{~min}$ and germinated 
in vitro. Ninety-one \% of the pollen grains germinated after 240 days of storage, and more than $80 \%$ of pollen maintained their germination ability after 480 days of storage using these two methods [55].

$\mathrm{Xu}$ et al. [54] reported the successful cryopreservation of Oriental hybrid 'Siberia' pollen, using rapid freezing and PVS2 vitrification. In rapid cooling, pollen was transferred into cryotubes that were directly plunged into LN. Frozen cryotubes were removed from $\mathrm{LN}$ and rewarmed in a water bath set at $37^{\circ} \mathrm{C}$ for $2 \mathrm{~min}$. In vitrification, pollen were suspended in 2-mL microcentrifuge tubes, each containing $1.5 \mathrm{~mL} 0.01 \mathrm{M}$ phosphate-buffered saline (PBS; $137 \mathrm{mM} \mathrm{NaCl}+2.7 \mathrm{mM} \mathrm{KCl}+4.3 \mathrm{mM}$ $\left.\mathrm{Na}_{2} \mathrm{HPO}_{4}+1.4 \mathrm{mM} \mathrm{KH} \mathrm{HO}_{4} ; \mathrm{pH} 7.2\right)$ to produce about $50 \mu \mathrm{L}$ of packed pollen. Packed pollen was treated with a loading solution containing $0.4 \mathrm{M}$ sucrose and $2 \mathrm{M}$ glycerol for $20 \mathrm{~min}$ at $25^{\circ} \mathrm{C}$, followed by exposure to PVS2 for $50 \mathrm{~min}$ in an ice bath, prior to direct immersion in LN. Cryopreserved pollen were thawed, as described above for rapid cooling and then unloaded with $1.2 \mathrm{M}$ sucrose at $25{ }^{\circ} \mathrm{C}$ for $10 \mathrm{~min}$. Pollen viability, which was determined by the triphenyltetrazolium chloride reduction assay [56], was about 59\% for rapid cooling and $70 \%$ for vitrification, both of which were significantly higher than $47 \%$ of the fresh (non-treated control) pollen.

Reactive oxidative species (ROS) are molecules that contain the element oxygen and are produced in plants under abiotic and biotic stress [57]. ROS-induced oxidative stress is closely related to pollen viability following cryopreservation $[54,58]$. Viability of Oriental hybrid 'Siberia' pollen after rapid cooling (59\%) and vitrification $(70 \%)$ was significantly greater than that (47\%) of the freshly collected pollen without any treatment [54]. Analysis of reactive oxygen species (ROS) found that
ROS levels significantly increased during vitrification procedure. Similar results were reported for cryopreserved pollen in Paeonia suffruticosa [58]. However, results obtained in the same group showed that increased ROS levels resulted in decreased viability of cryopreserved pollen in Jasminum nudiflorum, Malus spectabilis, Philadelphus pekinensis, Syringa oblate and Xanthoceras sorbifolium [58]. These data indicate ROS levels affected viability of cryopreserved pollens and responses to ROS levels vary with plant species.

A list of successful cryopreservation of Lilium pollen is presented in Table 2 and Fig. 2a, b.

\section{Seeds}

Lilium species, especially wild species, can be propagated by seeds. Therefore, seed cryopreservation can be considered an important strategy for the long-term preservation of Lilium germplasm. Studies on storage behavior of Lilium seeds are quite limited. A recent study [59] identified the seeds of L. polyphyllum had orthodox storage behavior. Seeds contain low moisture content after dispersal and can be dried to $5 \%$ or lower.

Two groups from Iran conducted a series of studies on cryopreservation of $L$. ledebourii seeds [27-29, 60-62] and developed various cryogenic protocols for this species, including encapsulation-dehydration [27, 29, 60], encapsulation-vitrification [61], pregrowth-desiccation $[28,62]$, vitrification and dessiccation and glycerol pretreatment [29]. A list of successful cryopreservation of Lilium seeds is presented in Table 2 and Fig. 2c, d.

Mohajeri et al. [29] used vitrification, encapsulation-vitrification, glycerol pretreatment and pregrowthdesiccation procedures to assess their effects on the cryopreservation of $L$. ledebourii seeds. Seeds that had

Table 2 A list of successful cryopreservation of Lilium pollens and seeds

\begin{tabular}{|c|c|c|c|}
\hline Species or hybrids & Cryo-methods & Survival or germination (\%) & Refs. \\
\hline \multicolumn{4}{|l|}{ Pollens } \\
\hline Oriental hybrid 'Sorbonne' and 'Siberia' & Desiccation & 60 and 59 after 60 days, and 51 and 48 after 420 days & [53] \\
\hline Oriental hybrid 'Siberia' & Rapid cooling & 59 & [54] \\
\hline Oriental hybrid 'Siberia' & Vitrification & 70 & {$[54]$} \\
\hline L. concolor var. pulchelium & Desiccation + rapid cooling & 21-92 (according to the conservation duration) & {$[55]$} \\
\hline \multicolumn{4}{|l|}{ Seeds } \\
\hline L. ledebourii & Encapsulation-dehydration & 50 & {$[27,60]$} \\
\hline L. ledebourii & Pregrowth-dehydration & 75 & {$[28]$} \\
\hline L. ledebourii & Encapsulation-vitrification & 10 & {$[61]$} \\
\hline \multirow[t]{4}{*}{ L. ledebourii } & Vitrification & 97 & [29] \\
\hline & Desiccation & 95 & \\
\hline & Encapsulation-dehydration & 69 & \\
\hline & Glycerol pretreatment & 98 & \\
\hline L. martagon & Dehydration & $93-100$ & {$[64]$} \\
\hline
\end{tabular}


been stored at $2-4{ }^{\circ} \mathrm{C}$ for 6 weeks without surface-disinfection were used for cryopreservation. In vitrification, seeds contained in $1.8-\mathrm{mL}$ cryotubes were treated with a loading solution composed of $2 \mathrm{M}$ glycerol and $0.4 \mathrm{M}$ sucrose for $20 \mathrm{~min}$ at $22{ }^{\circ} \mathrm{C}$ and then exposed to pre-cold PVS2 for $20 \mathrm{~min}$, followed by direct immersion in LN for cryostorage. In encapsulation-dehydration, seeds were encapsulated, as described by Kaviani et al. [61]. The beads were air-dried, as described by Kaviani et al. [61] for $3 \mathrm{~h}$ and transferred into $1.8-\mathrm{mL}$ cryotubes, followed by direct immersion in LN for cryostorage. In glycerol pretreatment, seeds contained in $1.8-\mathrm{mL}$ cryotubes were pretreated with $30 \%$ glycerol at $22{ }^{\circ} \mathrm{C}$ for $20 \mathrm{~min}$. Cryotubes were then directly immerged in LN for cryostorage. In desiccation, seeds were placed in a desiccator containing $300 \mathrm{~g}$ silica gel for $21 \mathrm{~h}$ at $22^{\circ} \mathrm{C}$. The desiccated seeds were transferred into $1.8-\mathrm{mL}$ cryotubes and directly plunged in LN for cryostorage. In all the four protocols tested, seeds cryopreserved in $\mathrm{LN}$ for 1 week were rapidly thawed in a water bath set at 40 for 2 min, and post-thaw cultured for germination on wet filter papers in $10-\mathrm{cm}$ Petri dishes. The cultures were placed in a growth chamber at $22{ }^{\circ} \mathrm{C}$ with a $16 \mathrm{~h}$ photoperiod (light intensity not specified in the article) for 32 days. Seed germination percentage was about $98 \%, 97 \%$ and $95 \%$ in glycerol pretreatment, vitrification and desiccation, respectively, and much higher than $69 \%$ in encapsulation-dehydration. Although there were no significant differences in root length, shoot length was greater in seedlings recovered from cryopreserved seeds by glycerol pretreatment, vitrification and desiccation than in those by encapsulationdehydration [29]. Glycerol treatment and desiccation avoid of use of toxic chemicals such as DSMO, which are required in vitrification, and easy to handle, and therefore, are recommended for cryopreservation of Lilium seeds [29].

Compared with the results obtained in the three cryoprocedures [29], as discussed above, only $10 \%$ survival levels of cryopreserved $L$. ledebourii seeds were obtained in encapsulation-vitrification [61], 50\% in encapsulation-dehydration $[27,60,61]$ and $75 \%$ in pregrowth-desiccation $[26,28]$.

Urbaniec-Kiepura and Bach [61] reported an improved pregrowth-desiccation protocol for cryopreservation of $L$. martagon seeds. In their study, seeds were cold-stored at $5{ }^{\circ} \mathrm{C}$ or $15{ }^{\circ} \mathrm{C}$ for 26 weeks. Following cold-storage, seeds were incubated on half-strength MS containing $0.75 \mathrm{M}$ sucrose for $1 \mathrm{~h}$, followed by desiccation by air-drying to reduce the moisture content of the seeds to $13.1 \%$, prior to freezing in LN. With this protocol, $93-100 \%$ of seeds germinated following cryopreservation and seed germination time was shortened by about 34 days, compared with 41 days in non-cryopreserved seeds. A list of successful cryopreservation of Lilium seeds can be found in Table 2, and Fig. 2c, d.

\section{Comparison of cryopreservation efficiency}

Matsumoto and Sakai [30], and Matsumoto et al. [31] compared effects of vitrification, encapsulation-vitrification and two encapsulation-dehydration procedures on shoot regrowth of cryopreserved shoot tips of L. japonicum 'Japanese Lily'. In the first encapsulation-dehydration, the beads were precultured with $0.8 \mathrm{M}$ sucrose, before dehydration, while in the second encapsulationdehydration, the beads were precultured with $0.8 \mathrm{M}$ sucrose and 1.0 M glycerol, before dehydration. Vitrification and encapsulation-vitrification produced 92-94\% shoot regrowth levels, which were similar to $88 \%$ produced in the second encapsulation-dehydration procedure, but significantly higher than $67 \%$ produced in the first encapsulation-dehydration procedure. Matsumoto and Sakai [30], and Matsumoto et al. [31] attributed the improve shoot regrowth of cryopreserved shoot tips to glycerol treatment used in preculture by minimizing the cell membrane injury caused by dehydration. Responses to cryo-methods varied among Lilium genotypes [36]. Droplet-vitrification produced much higher shoot regrowth levels in Oriental hybrid 'Siberia' (65\%) and L. lancifolium (84\%) than vitrification in the corresponding lilies (35\% and 36\%). However, these two cryomethods produced similar recovery levels (43\% and $33 \%$ ) in L. $\times$ longiflorum [36].

\section{Genetic stability}

When samples are cryopreserved, cellular divisions halt, and theoretically, plant materials can be preserved for an extended length of time, while maintaining genetic stability [20-23, 63]. However, each of the necessary cryopreservation steps including preculture, cryoprotection, PVS exposure, thawing and post-thaw culture may cause physical or chemical stress, which subsequently may alter the genetic stability of plants recovered after cryopreservation [20-23, 63]. In addition, in vitro tissue culture techniques are also required for production of in vitro stock cultures and shoot regrowth after cryopreservation. In vitro tissue culture may induce genetic variations [64]. Therefore, the assessment of genetic integrity of regenerants recovered after cryopreservation is often performed [20-23, 34, 63].

To date, there have been only a few studies that evaluated morphology and assessed genetic integrity of the regenerants recovered after cryopreservation in Lilium [32, 35, 36, 43]. No differences in morphological traits including plant height, leaf length, leaf width and leaf color were observed between plants recovered from droplet-vitrification and vitrification cryopreservation 
of shoot tips and those of the control $[32,36]$. No phenotypic differences were identified in three Lilium hybrids, L. bolanderi and L. davidii in plants recovered from shoot tips that were and were not exposed to LN, except the height of the LN-exposed L. bolanderi plants was slightly less than that of the controls [43]. Similar soluble protein and isoenzyme patterns were found in the plants recovered after shoot tips were cryopreserved by vitrification and the controls [34]. The use of inter-simple sequence repeat markers (ISSR) detected no differences in plants recovered from shoot tips that were and were not cryoexposed using droplet-vitrification techniques [35].

\section{Advances in improvements of explant production, cryopreservation efficiency and regenerative patterns of cryopreserved shoot tips}

In many of the studies on the cryopreservation of Lilium shoot tips, adventitious buds induced from the bulb scales were cold-hardened at $0-5^{\circ} \mathrm{C}$ for 5 days to 3 weeks and shoot tips excised from the cold-hardened stock cultures were used for cryopreservation [24, 30, 31, 34, 36, 47]. Cold-hardening of in vitro stock cultures requires a temperature-controlled growth chamber and is also time consuming. The droplet-vitrification protocol described by Yin et al. [35] eliminated cold-hardening of the in vitro stock cultures and at the same time produced high recovery levels (averaging at 67\%) in six lily genotypes belonging to five Lilium species and hybrids.

In all studies so far reported for shoot tip cryopreservation, excision of shoot tips is a necessary step. This step requires skilled staff, and is the most time-consuming and labor-intensive in the whole cryoprocedures [65]. In addition, surgical excision of shoot tips from stock cultures may cause physical damage to and induce browning of explants. Recently, Pan et al. [33] reported the cryopreservation of small leaf squares-bearing adventitious buds of $L$. Oriental hybrid 'Siberia'. In that study, adventitious buds were induced from leaf segments, as described by Yin et al. [35]. After 12 days of induction culture, small leaf squares $(3 \times 4 \mathrm{~mm}$, Fig. $2 \mathrm{j})$, each bearing at least one adventitious bud, were cut from leaf segments and subject to cryopreservation, according to Yin et al. [35]. With this procedure, $85 \%$ survival and $72 \%$ shoot regrowth were achieved following cryopreservation, with at least one shoot developed in each of the cryopreserved small leaf squares (Fig. 2k). Plantlets with a good root system formed after 4 weeks of culture on rooting medium (Fig. 2l). The use of small leaf squares bearing adventitious buds for cryopreservation eliminated the timeconsuming and labor-intensive step of shoot tip excision, thus facilitating shoot tip cryopreservation.
In vitrification cryopreservation, cryotubes of 1.8 $2.0 \mathrm{~mL}$ cryotubes are usually used. Working on vitrification for cryopreservation of L. lancifolium shoot tips, $\mathrm{Xu}$ et al. [49] found much higher survival levels (95\%) were obtained when small cryotubes $(200 \mu \mathrm{L})$ were used than those $(75 \%)$ produced by large cryotubes $(1.0 \mathrm{~mL})$. Improved effects of small cryotubes on recovery of cryopreserved shoot tips are most likely due to faster cooling/ warming rates produced in cryotubes with a smaller volume [45].

Somatic embryogenesis has potential applications to micropropagation and genetic transformation in Lilium [13, 66-68]. Establishment of somatic embryogenic tissues is time- and labor-consuming. Some lilies are still recalcitrant to somatic embryogenesis [66-68]. Once established, somatic embryogenic tissues need to be repeatedly subcultured to maintain their regenerative ability. Subculture has risks of contamination, thus resulting in total loss of the cultures, and regenerative ability of the embryogenic tissues decreases as times of subculture increase $[67,68]$. Cryopreservation of somatic embryogenic tissues appeared to be difficult and to our knowledge no studies have been published in Lilium. Use of different post-culture media for recovery of shoot tips following droplet-vitrification as described by Yin et al. [35], Bi et al. [37] achieved three types of regenerants: (1) only embryo-like structures (Fig. 2h), (2) shoot regrowth with embryo-like structures, and (3) only shoot regrowth. The highest frequencies $(\geq 75.0 \%)$ of total embryo-like structures were obtained from cryopreserved shoot tips post-cultured on the recovery medium containing $0.1 \mathrm{mg}$ $\mathrm{L}^{-1}$ NAA and $0.1-0.2 \mathrm{mg} \mathrm{L}^{-1}$ kinetin (KT). The highest frequencies $(\geq 25 \%)$ of total shoot regrowth were produced from cryopreserved shoot tips post-cultured on recovery medium containing $0.1 \mathrm{mg} \mathrm{L}^{-1} \mathrm{NAA}$ and $0.05-$ $0.4 \mathrm{mg} \mathrm{L}^{-1} \mathrm{KT}$. Frequencies of total embryo-like structures and shoot regrowth ranged from $45 \%$ to $90 \%$ and 25 to $53 \%$, respectively, from six lily varieties belonging to five Lilium species or hybrids [37]. These embryo-like structures developed into somatic embryos and germinated (Fig. 2i) into whole plantlets when cultured on MS medium containing $90 \mathrm{~g} \mathrm{~L}^{-1}$ sucrose. This cryo-method provides alternative to cryopreservation of somatic embryogenic tissues in Lilium.

\section{Future prospects and conclusion}

A number of valuable genes and transcription factors that regulate flower time, and flower shape, color and scent, as well as those resistant/tolerant to abiotic stresses have been reported in the genus Lilium [3, 50, 69-79]. For example, genes and transcription factors that regulate coloration and pigmentation were obtained in Asiatic hybrids [70-75] and L. lancifolium [76]. Genes encoding 
resistance to abiotic stresses such as cold, drought and salt were isolated from L. lancifolium and L. regale [78, 79]. Diseases induced by fungi such as Fusarium wilt and leaf blight [80, 81], and viruses such as cucumber mosaic virus (CMV), lily mottle virus (LMoV), lily symptomless virus (LSV) and tulip breaking virus (TBV) [80] cause severe damage to the lily industry. Genes encoding resistance to fungal and viral diseases have been found, including those resistant to Fusarium wilt in Asiatic hybrids [81] and L. regale [82-85], leaf blight in L. regal [86, 87], and TBV and LMoV in Longiflorum [72, 88, 89], Asiatic hybrids [73] and L. regal [74]. These valuable genes have been/are being used for breeding of novel cultivars resistant to abiotic and biotic stresses in classic and biotechnological strategies in Lilium [13, 72, 74-76, 85]. Cryopreservation of these valuable genes will certainly ensure supply genetic resources for breeding of novel lily cultivars in the future.

The droplet-vitrification method, which was developed by Panis et al. [41] for cryopreservation of the diverse genetic resources of the genera Musa and Ensete and has been widely used for cryopreservation of a huge number of plant species [20-22], was also proven to be the most applicable to a wide range of Lilium species, hybrids and cultivars [33-35], and should be tested to determine if they can be used to develop Lilium cryobanks for diverse genetic resources. It may be particularly valuable to cryopreserve Asiatic and Oriental hybrid lilies that contain key flower trait genes of interest and $L$. regale that is resistant to biotic and abiotic stress. Additional seed cryopreservation and longevity studies are also needed for both wild and cultivated species. Although several methods have been described for cryopreserving Lilium pollen $[25,53,54]$, there was documentation of the use of cryopreserved pollen for making crosses and producing viable seeds. More studies that assess genetic stability in plants recovered after cryopreservation are needed to confirm that there are no genetic changes resulting from cryoexposure [35, 36, 68]. This additional research will aid in the development of Lilium cryobanks. Nevertheless, more studies are still needed to accelerate settingup of cryo-bankings of diverse genetic resources in the genus Lilium.

At this time, there are no reports of the cryopreservation of Lilium somatic embryogenic tissue. Successful cryopreservation of somatic embryogenic tissues would facilitate the development of somatic embryogenesis applications in biotechnology programs in Lilium.

Virus diseases cause great economic losses in Lilium production [80]. Lilium elite cultivars used for flower production are vegetatively propagated and are therefore prone to virus infection [80]. Cryotherapy, a novel biotechnology for pathogen eradication [39], has been applied to 21 plant species and has successfully eradicated 28 viruses belonging to 18 genera of 8 families and one unassigned family [90]. Development of cryotherapy for production of virus-free plants would assist sustainable development of the Lilium industry.

\section{Authors' contributions \\ J-WL: collection and analysis of data, and preparation of manuscript; X-CZ: assistance to collection and analysis of data; W-LB and M-RW: providing valuable data and assistance to preparation of manuscript; MF: valuable dis- cussion; JATS: valuable discussion and editing: GMV: valuable discussion and editing; Q-CW: chief scientist, providing financial supports and preparation of manuscript. All authors read and approved the final manuscript.}

\section{Funding}

This research was funded by National Natural Science Foundation of China (No. 31701761), Chinese Universities Scientific Fund (No. 2452017061) and Department of Science and Technology of Shaanxi Province, China (2014KTCL02-05).

\section{Availability of data and materials}

Not applicable.

Ethics approval and consent to participate

Not applicable.

\section{Consent for publication}

Not applicable.

\section{Competing interests}

The authors declare that they have no competing interests.

\section{Author details}

${ }^{1}$ State Key Laboratory of Crop Stress Biology in Arid Region, College of Horticulture, Northwest A\&F University, Yangling 712100, Shaanxi, People's Republic of China. ${ }^{2}$ College of Agronomy, Guizhou University, Guiyang 550025, Guizhou, People's Republic of China. ${ }^{3}$ Gosling Research Institute for Plant Preservation (GRIPP), Department of Plant Agriculture, University of Guelph, Bovey Bldg, Room 4227, Guelph, ON, Canada. ${ }^{4}$ Department of Botany \& Microbiology, College of Science, King Saud University, P.O. Box 2455, Riyadh 11451 , Saudi Arabia. ${ }^{5}$ P. O. Box 7, Miki-cho Post Office, Ikenobe 3011-2, Kagawa-ken 761-0799, Japan. ${ }^{6}$ National Laboratory for Genetic Resources Preservation, 1111 S. Mason St, Fort Collins, CO 80521, USA.

Received: 29 March 2019 Accepted: 18 October 2019

Published online: 02 November 2019

\section{References}

1. Pelkonen VP, Pirttilä AM. Taxonomy and phylogeny of the genus Lilium. In: van Tuyl JM, Arens P, editors. Floriculture \& ornamental biotechnology. London: Global Science Books; 2012. p. 9-23.

2. Wu XW, Tian M, Wang LH, Cui GF, Yu RP, Lu ZH, Jia WJ, Qu SP, Gui M, Wang JH. Native species of the genus Lilium in China. Acta Hortic. 2014;1027:27-40

3. Van Tuyl JM, Arens P, Ramanna MS, Shahin A, Khan N, Xie S, Marasek-Ciolakowska A, Lim KB, Barba-Gonzalez R. Lilium. In: Kole Ch, editor. Wild crop relatives: genomic and breeding resources, plantation and ornamental crops. Berlin: Springer; 2011. p. 161-208.

4. Bakhshaie M, Khosravi S, Azadi P, Bagheri H, van Tuyl MJ. Biotechnological advances in Lilium. Plant Cell Rep. 2016;35:1799-826.

5. Mu D, Yi MF, Xia Y. Production and cultivation of lilies in china. Acta Hortic. 2014;1027:97-103.

6. Zhao B, Zhang J, Guo X, Wang J. Microwave-assisted extraction, chemical characterization of polysaccharides from Lilium davidii var. unicolor Salisb and its antioxidant activities evaluation. Food Hydrocoll. 2013;31:346-56. 
7. Wu XM. Studies on nutrient composition of Lilium davidii var. unicolorderived products. Food Nutr China. 2017;23:77-80.

8. Ai QY, Kang SY, Zhao YF. Advances in studies and applications of lilies as Chinese medicine. J Yunnan Univ. 2016;14:63-5.

9. Jin L, Zhang Y, Yan L, Guo Y, Niu L. Phenolic compounds and antioxidant activity of bulb extracts of six Lilium species native to China. Molecules. 2002;17:9361-78.

10. Haw SG, Liang SY. The lilies of China: the genera Lilium, Cardiocrinum, Nomocharis and Notholirion. Portland: Timber Press; 1986.

11. Khan N, Marasek-Ciolakowska A, Xie S, Ramanna MS, van Tuyl JM. A molecular cytogenetic analysis of introgression in backcross progenies of intersectional Lilium hybrids. In: van Tuyl JM, Arens P, editors. Floriculture \& ornamental biotechnology. London: Global Science Books; 2012. p. $13-20$.

12. Arens $P$, Shahin A, vanTuly JM. Molecular breeding of Lilium. Acta Hortic. 2014;1027:113-27.

13. Liu X, Gu J, Wang J, Lu Y. Lily breeding by using molecular tools and transformation systems. Mol Biol Rep. 2014;41:6899-908.

14. Guo W, Jeong J, Kim Z, Wang R, Kim E, Kim S. Genetic diversity of Lilium tsingtauense in China and Korea revealed by ISSR markers and morphological characters. Biochem Syst Ecol. 2011;39:352-60.

15. Rana MS, Samant SS. Population biology of Lilium polyphyllum D. Don ex Royle - a critically endangered medicinal plant in a protected area of Northwestern Himalaya. J Nat Conserv. 2011;19:137-42.

16. America's Climate Choices. Washington, D.C.: The National Academies Press 978-0-309-14585-5; 2011. https://www.nap.edu/catalog/12781/ Americas-Climate-Choices.

17. Casazza G, Carta A, Giordani P, Guerrina M, Peruzzi L, Minuto L. Reproductive biology of the threatened Lilium pomponium (Liliaceae), a species endemic to Maritime and Ligurian Alps. J Plant Res. 2018;131:633-40.

18. Rossi et al. Montagani C, Gargano D. In: Lista rossa della flora italiana. 1. Policy species e altre specie minacciate. https://www.nationalredlist .org/lista-rossa-della-flora-italiana-1-policy-species-e-altre-specie-minac ciate-2013-red-list-of-italian-flora-1-policy-species-and-other-threatened -species-italian.

19. Arate-Fernändez AM, Miwa M, Shimada T, Yonekura T, Ogawa K. Genetic diversity of Miyamasukashi-yuri (Lilium maculatum Thunb. var. bukosanense), an endemic and endangered species at Mount Buko, Saitama, Japan. Plant Species Biol. 2005;20:57-65.

20. Wang B, Wang RR, Cui ZH, Bi WL, Li JW, Li BQ, Ozudogru AE, Volk GM, Wang QC. Potential applications of cryogenic technologies to plant genetic improvement and pathogen eradication. Biotechnol Adv. 2014;32:583-95

21. Wang MR, Chen L, Teixeira da Silva JA, Volk GM, Wang Q-C. Cryobiotechnology of apple (Malus spp.): development, progress and future prospects. Plant Cell Rep. 2018;37:689-709.

22. Li JW, Ozudogru EA, Li J, Wang M-R, Bi WL, Lambardi M, Wang Q-C. Cryobiotechnology of forest trees: recent advances and future prospects. Biodivers Conserv. 2017;27:795-814.

23. Harding K. Genetic integrity of cryopreserved plant cells: a review. CryoLetters. 2004;25:3-22.

24. Bouman HD, de Klerk GJ. Cryopreservation of lily meristems. Acta Hortic. 1990;266:331-7.

25. Geng XM, Qiu JY, Okubo H. Changes of carbohydrate content during Lilium and Gladiolus pollen cryopreservation. Grana. 2013;52:202-6.

26. Kaviani B. Cryopreservation of seeds of lily [Lilium ledebourii (Baker) Bioss.]: use of sucrose and dehydration. Int J Eng Technol. 2009;1:291.

27. Kaviani B. Cryopreservation by encapsulation-dehydration for long-term storage of some important germplasm: seed of lily [Lilium ledebourii (Baker) Bioss.], embryonic axe of persian lilac (Melia azedarach L.), and tea (Camellia sinensis L.). Plant Omics. 2010;3:177-82.

28. Kaviani B, Abadi DH, Torkashvand AM, Hoor SS. Cryopreservation of seeds of lily (Lilium iedebourii (baker) bioss): use of sucrose and dehydration. Afr J Biotechnol. 2009:8:3809-10.

29. Mohajeri MR, Zare AG, Shahab MAN, Jari SK. Seed germination of Lilium ledebourii (Baker) Boiss. after cryopreservation. J Rangeland Sci. 2014;4:279-85.

30. Matsumoto T, Sakai A. An approach to enhance dehydration tolerance of alginate-coated dried meristems cooled to $-196^{\circ} \mathrm{C}$. CryoLetters. 1995;16:299-306
31. Matsumoto T, Sakai A, Yamada K. Cryopreservation of in vitro-grown apical meristems of lily by vitrification. Plant Cell Tissue Organ Cult. 1995:41:237-41.

32. Chen $H$, Chen XL, Chen LQ, Lu XX. Cryopreservation of shoot tips from in vitro plants of our flower of lily (Lilium L.) by vitrification method. J Plant Gene Res. 2007;2:170-3.

33. Pan C, Liu J, Bi WL, Chen H, Engelmann F, Wang QC. Cryopreservation of small leaf squares-bearing adventitious buds of Lilium Oriental hybrid 'siberia' by vitrification. Plant Cell Tissue Organ Cult. 2018;133:159-64.

34. Yi JY, Lee GA, Chung JW, Lee SY, Lim KB. Efficient cryopreservation of Lilium spp. shoot tips using droplet-vitrification. Plant Breed Biotechnol. 2013;1:131-6.

35. Yin ZF, Bi WL, Chen L, Zhao B, Volk GM, Wang QC. An efficient, widely applicable cryopreservation of Lilium shoot tips by droplet vitrification. Acta Physiol Plant. 2014;36:1683-92.

36. Chen XL, Li JH, Xin X, Zhang ZE, Xin PP, Lu XX. Cryopreservation of in vitro-grown apical meristems of Lilium by droplet-vitrification. S Afr J Bot. 2011;77:397-403.

37. Bi WL, Yin ZF, Guo L, Chen L, Pan C, Wang QC. Plant regeneration from shoot regrowth and de novo embryo-like structures from cryopreserved shoot tips of Lilium spp. Vitro Cell Dev Biol Plant. 2015;51:390-8.

38. Urbaniec-Kiepura M, Bach A. Cryopreservation of Lilium martagon L. meristems by droplet-vitrification and evaluation of their physiological stability. CryoLetters. 2017;38:78-89.

39. Wang QC, Valkonen JPT. Cryotherapy of shoot tips: novel pathogen eradication method. Trends Plant Sci. 2009:14:119-22.

40. Fahy GM, MacFarlane DR, Angell CA, Meryman HT. Vitrification as an approach to cryopreservation. Cryobiology. 1984;21:407-26.

41. Panis B, Piette B, Swennen R. Droplet vitrification of apical meristems: a cryopreservation protocol applicable to all Musaceae. Plant Sci. 2005; 168:45-55

42. Sakai A, Engelmann F. Vitrification, encapsulation-vitrification and droplet-vitrification: a review. CryoLetters. 2007;28:3151-72.

43. Yi JY, Lee GA, Lee SY, Chung JW. Development of cryo-banking system of Lilium species. Flower Res J. 2014;22:185-9.

44. Murashige T, Skoog F. A revised medium for rapid growth and bioassays with tobacco cell cultures. Physiol Plant. 1962;15:473-97.

45. Sakai A, Kobayash S, Oiyama I. Cryopreservation of nucellar cells of navel orange (Citrus sinensis Osb. var. brasiliensis Tanaka) by vitrification. Plant Cell Rep. 1990;9:30-3.

46. Nishizawa S, Sakai A, Amano Y, Matsuzawa T. Cryopreservation of asparagus (Asparagus officinalis) embryogenic suspension cells and subsequent plant regeneration by vitrification. Plant Sci. 1993;91:67-73.

47. Jeon SM, Naing AH, Kim HH, Chung MY, Lim KB, Kim CK. Elimination of chrysanthemum stunt viroid and chrysanthemum chlorotic mottle viroid from infected chrysanthemum by cryopreservation. Protoplasma. 2017;253:1135-44.

48. Bouman H, Tiekstra A, Petutschnig E, Homan M, Schreurs R. Cryopreservation of Lilium species and cultivars. Acta Hortic. 2003;612:147-54.

49. Xu J, Liu Y, Li BL, Liu Q, Shi Y, Jia MX, Shen C. Protective effect of reducing cryotube volume on Lilium lancifolium and Euonymus fortunei shoot tips survival after cryopreservation by vitrification. Acta Hortic. 2015;1104:255-8.

50. Shahin A. Development of genomic resources for ornamental lilies (Lilium L.). Dissertation, Wageningen University. 2012.

51. He G, Hu F, Ming J, Liu C, Yuan S. Pollen viability and stigma receptivity in Lilium during anthesis. Euphytica. 2017;213:231-40.

52. Zhang Y, Chen RD, Huang CJ, Liu Y. Cryo-banking of Prunus mume pollen and its application in cross-breeding. CryoLetters. 2009:30:165-70.

53. Shi TT, Zhang GL, Wen SM, Lu JL. Cryopreservation of Lilium pollens. North Hortic. 2013;13:64-6.

54. Xu J, Liu Q, Jia M, Liu Y, Li B, Shi Y. Generation of reactive oxygen species during cryopreservation may improve Lilium $\times$ Siberia pollen viability. Vitro Cell Dev Biol-Plant. 2014;50:369-75.

55. Zhao P, Zhang QW, Shi BS, Liu Y. Studies on cryopreservation of Lilium concolor var. pulchelium. J Agric Univ Hebei. 2014;37:54-8.

56. Steponkus PL, Lanphear FO. Refinement of the triphenyltetrazolium chloride method of determining cold injury. Plant Physiol. 1967;42:1423-6. 
57. Cui ZH, Bi WL, Hao XY, Xu Y, Li PM, Walker MA, Wang QC. Responses of in vitro-grown plantlets (Vitis vinifera) to grapevine leafroll-associated virus-3 and peg-induced drought stress. Front Physiol. 2016;7:203. https:// doi.org/10.3389/fphys.2016.00203.

58. Jia MX, Shi Y, Di W, Jiang XR, Xu J, Liu Y. ROS-induced oxidative stress is closely related to pollen deterioration following cryopreservation. Vitro Cell Dev Biol-Plant. 2017;53:433-9.

59. Dhyani A, Baskin CC, Nautiyal BP, Nautiyal BP, Nautiyal MC. Overcoming root dormancy and identifying the storage behaviour of Lilium polyphyllum seeds. Botany. 2019;97:161-6.

60. Kaviani B, Dehkaei MNP, Safarimotlagh MR, Darabi AH, Rafizadeh A. Cryopreservation of lily [Liliunm ledebourii (Baker) Bioss.] germplasm by encapsulation-dehydration. J Biotechnol. 2008;136:S273.

61. Urbaniec-Kiepura M, Bach A. Effects of pre-storage on Lilium martagon L. seed longevity following cryopreservation. CryoLetters. 2014;35:462-72.

62. Kaviani B, Dahkaei M, Hashemabadi D, Darabi A. Cryopreservation of Lilium ledebourii (Baker) Bioss. by encapsulation-vitrification and in vivo media for planting of germplasm. Am Eur J Agric Environ Sci. 2010;8:556-60.

63. Benson EE. Cryopreservation of phytodiversity: a critical appraisal of theory practice. Crit Rev Plant Sci. 2008;27:141-219.

64. Gudeva KL, Trajkova F (2015) The effect of plant growth regulators on morphogenesis in tissue culture of some agricultural species. In: The 6th international scientific agricultural symposium, Agrosym 2015, pp 238-244

65. Harvengt L, Meierdinkel A, Dumas E, Collin E. Establishment of a cryopreserved gene bank of European elms. Can J Forest Res. 2004;34:43-55.

66. Nakano M, Sakakibara T, Suzuki S, Saito H. Decrease in the regeneration potential of long-term cell suspension cultures of Lilium formosanum Wallace and its restoration by the auxin transport inhibitor, 2,3,5-triiodobenzoic acid. Plant Sci. 2000;158:129-37.

67. Nhut DT, Le BV, Teixeira da Silva JA, Aswath CR. Thin cell layer culture system in Lilium: regeneration and transformation perspectives. In Vitro Cell Dev Biol Plant. 2001;37:516-23.

68. Bi WL, Chen L, Guo L, Pan C, Yin ZF, Wang QC. Plant regeneration via embryo-like structures: histological observations and genetic stability in regenerants of Lilium spp. J Hortic Sci Biotechnol. 2015;90:626-34.

69. Yamagishi M. How genes paint lily flowers: regulation of colouration and pigmentation patterning. Sci Hortic. 2013;163:27-37.

70. Nakatsuka A, Izumi Y, Yamagishi M. Spatial and temporal expression of chalcone synthase and dihydroflavonol 4-reductase genes in the Asiatic hybrid lily. Plant Sci. 2003;165:759-67.

71. Lai YS, Shimoyamada Y, Nakayama M, Yamagishi M. Pigment accumulation and transcription of LhMYB12 and anthocyanin biosynthesis genes during flower development in the Asiatic hybrid lily (Lilium spp.). Plant Sci. 2012;193:136-47.

72. Yamagishi M, Toda S, Tasaki K. The novel allele of the LhMYB12 gene is involved in splatter-type spot formation on the flower tepals of Asiatic hybrid lilies (Lilium spp.). New Phytol. 2014;201:1009-20.

73. Yamagishi M, Ihara H, Arakawa K, Toda H, Suzuki K. The origin of the LhMYB12 gene, which regulates anthocyanin pigmentation of tepals, in Oriental and Asiatic hybrid lilies (Lilium spp.). Sci Hortic. 2014;174:119-25.

74. Yamagishi M, Shimoyamada Y, Nakatsuka T, Masuda K. Two R2R3-MYB genes, homologs of petunia AN2, regulate anthocyanin biosyntheses in flower tepals, tepal spots and leaves of Asiatic hybrid lily. Plant Cell Physiol. 2010;51:463-74.

75. Yamagishi M, Kishimoto S, Nakayama M. Carotenoid composition and changes in expression of carotenoid biosynthetic genes in tepals of Asiatic hybrid lily. Plant Breed. 2010;129:100-7.
76. Jeknić Z, Morre JT, Jeknić S, Jevremović S, Subotić A, Chen THH. Cloning and functional characterization of a gene for capsanthin-capsorubin synthase from tiger lily (Lilium lancifolium Thunb. 'Splendens'). Plant Cell Physiol. 2012;53:1899-912.

77. Shahin A, Arens P, Van Heusden AW, Van Der Linden G, Van Kaauwen M, Khan N, Schouten HJ, Van de Weg WE, Visser RGF, Van Tuyl JM. Genetic mapping in Lilium: mapping of major genes and quantitative trait loci for several ornamental traits and disease resistances. Plant Breed. 2011:130:372-82.

78. Wang J, Yang Y, Liu X, Huang J, Wang Q, Gu J, Lu Y. Transcriptome profiling of the cold response and signaling pathways in Lilium lancifolium. BMC Genomics. 2014;15:203.

79. Wei C, Cui Q, Zhang XQ, Zhao YQ, Jia GJ. Three P5CS genes including a novel one from Lilium regale play distinct roles in osmotic, drought and salt stress tolerance. J Plant Biol. 2016;59:456-66.

80. Chastagner GA, van Tuyl JM, Verbeek M, Miller WB, Westerdahl BB. Diseases of Lily. In: McGovern R, Elmer W, editors. Handbook of florists' crops diseases, handbook of plant disease management. Berlin: Springer; 2017. p. 1-61.

81. Krens F, Van Tuyl JM. Plant breeding in bulbous ornamentals: adding wit to chance. Acta Hortic. 2011;886:329-42.

82. Li H, Liu D, He H, Zhang N, Ge F, Chen C. Molecular cloning of a 14-3-3 protein gene from Lilium regale Wilson and overexpression of this gene in tobacco increased resistance to pathogenic fungi. Sci Hortic. 2014;168:9-16

83. He H, Liu D, Zhang N, Zheng W, Han W, Ji B, Ge F, Chen C. The PR10 gene family is highly expressed in Lilium regale Wilson during Fusarium oxysporum f. sp. lilii infection. Genes Genomics. 2014;36:497-507.

84. Rao J, Liu D, Zhang N, He H, Ge F, Chen C. Identification of genes differentially expressed in a resistant reaction to Fusarium oxysporum in Lilium regale by SSH. IERI Procedia. 2013;5:95-101.

85. Rao J, Liu D, Zhang N, He H, Ge F, Chen C. Differential gene expression in incompatible interaction between Lilium regale Wilson and Fusarium oxysporum f. sp. lilii revealed by combined SSH and microarray analysis. Mol Biol. 2014;48:802-12

86. Han Q, Rui C, Ye Y. A glutathione S-transferase gene from Lilium regale Wilson confers transgenic tobacco resistance to Fusarium oxysporum. Sci Hortic. 2016;198:370-8.

87. Zhang N, Guan R, Yang Y, Bai Z, Ge F, Liu D. Isolation and characterization of a Fusarium oxysporum-resistant gene $L r G L P 1$ from Lilium regale Wilson. Vitro Cell Dev Biol Plant. 2017;53:461-8.

88. Shahin A, Arens P, Van Heusden S, Van Tuyl JM. Conversion of molecular markers linked to Fusarium and virus resistance in Asiatic lily hybrids. Acta Hortic. 2009;836:131-6.

89. Sun DY, Zhang XG, Li SH, Jiang CZ, Zhang YL, Niu LX. Lrabcf1, a gen-type atp-binding cassette transporter from Lilium regale, is involved in defense responses against viral and fungal pathogens. Planta. 2016;244:1185-99.

90. Zhao L, Wang MR, Li JW, Cui ZH, Volk GM, Wang QC. Cryobiotechnology: a double-edged sword for obligate plant pathogens. Plant Dis. 2019. https ://doi.org/10.1094/PDIS-11-18-1989-FE.

\section{Publisher's Note}

Springer Nature remains neutral with regard to jurisdictional claims in published maps and institutional affiliations. 